\title{
Mechanical Properties, Morphology and Thermal Degradation of a Biocomposite of Polypropylene and Curaua Fibers: Coupling Agent Effect
}

\author{
Barbara Mano, Joyce R. Araujo, Marco-A. De Paoli \\ Instituto de Química, UNICAMP \\ Walter R. Waldman \\ Universidade Federal de São Carlos, UFSCar \\ Márcia A. Spinace \\ Universidade Federal do ABC, UFABC
}

\begin{abstract}
Biocomposites of polymers with vegetal fibers have a broad spectrum of applications due to their high specific properties in comparison to their counterparts made with fiberglass. Polypropylene, PP, composites with curaua fiber compatibilized with different concentrations of maleic anhydride grafted polypropylene, PP-g-MA, were characterized according to their mechanical properties, morphologies and thermal stabilities in oxidative and inert atmospheres. The composites were prepared by single screw extrusion and injection molded specimens were used for testing. The composite with $20 \mathrm{wt} \%$ of curaua fiber with and without compatibilizer presented improved mechanical properties compared to pure PP. The use of PP-g-MA as a compatibilizer significantly increased fiber/matrix adhesion, however, the mechanical properties were only slightly improved in comparison with composites without compatibilizer. We observed an improvement in thermal stability of the composites, compared to that expected from the weighted average of the individual components, both under inert and oxidative atmospheres. Furthermore, the thermal stability improved under inert atmosphere as a function of the concentration of compatibilizer. In this situation, indeed, there was a different shift of the weight loss processes owing to the presence of the compatibilizer.
\end{abstract}

Keywords: Thermal degradation, coupling agent, curaua fibres, biocomposites.

\section{Introduction}

Polymeric composites reinforced with short vegetal fibers have emerged as potential substitutes of glass fiber polymeric composites in many applications, mainly in the automotive industry ${ }^{[1,2,3]}$. These composites are mostly produced by thermoforming; however, they can be also produced by continuous large scale processes, like extrusion $^{[4,5]}$, and can be molded into detailed parts, with good surface finishing, by injection molding. In contrast to glass fibers, vegetal fibers are: less dense, obtained from renewable sources and biodegradable. The lower abrasivity to the processing equipment is also an important feature for industry, resulting in cost savings with maintenance ${ }^{[6,7]}$. Concerning composites, life cycle studies show that vegetal fiber composites are more sustainable and environmentally friendly in comparison to glass fiber composites, especially when it is considered that the production of the vegetal fibers has less environmental impact than the production of glass fibers. The composites with vegetal fibers generally have a larger volumetric amount of fibers for the same mechanical performance, reducing the relative amount of the non-degradable polymer matrix. For the automotive industries, the lower weight of car parts made of vegetal fiber composites results in reduction of the weight of the cars, reducing the consumption of fuels, and, consequently, greenhouse gas emission. The incineration of vegetal fiber composites produces more energy and carbon credits than glass fiber composites 1 . The vegetal fibers also represent social-economic interests for agriculture, promoting growth and development in the areas of cultivation of the plant and extraction of the fibers ${ }^{[8]}$.

Besides their advantages, there are some drawbacks to using vegetal fibers, like poor thermal stability, mainly in processing conditions, high flammability and hydrophilicity. Thermal decomposition begins above $220{ }^{\circ} \mathrm{C}$, limiting the processing temperature and, consequently, the range of polymers to be used as matrices ${ }^{[9]}$. The hydrophilic character makes them incompatible with hydrophobic polymers, like polyolefins, restricting the mechanical charge transfer between the polymeric matrix and the fibers. To overcome this drawback, some strategies to promote larger polymer-fiber contact can be applied, like fiber surface treatment, polymer modification or introduction of coupling agents ${ }^{[10,11]}$. For polyolefins, polymers grafted with maleic anhydride are commonly used as coupling agent ${ }^{[12]}$. In this case the agent is mainly localized at the polymer/fiber interface, with the polymeric component of the coupling agent interacting with the hydrophobic polymer matrix and the maleic anhydride interacting with the hydrophilic fibers ${ }^{[9,5]}$, promoting adhesion between the two phases ${ }^{[13]}$.

Curaua fibers have been extensively studied for composites with thermosets and thermoplastics because of the fact that their remarkable mechanical properties in relation to other vegetal fibers produced on a large scale, e.g. sisal or jute ${ }^{[14]}$. Its composite with polyamide- 6 shows properties comparable to industrially produced composites with glass fibers ${ }^{[15]}$. By these reasons it is important to study the effect of the presence of the fiber and coupling agent on the thermal stability of the composites with polypropylene prepared by extrusion.

In this work we studied the effect of the coupling agent, and its concentration, on the morphology and mechanical properties of composites of polypropylene and curaua fibers. We also discuss the thermal degradation process of these composites, considering the coupling agent presence. 


\section{Experimental}

\section{Materials}

Isotactic polypropylene (PP, grade H301) (MFI: $10 \mathrm{~g} 10 \mathrm{~min}^{-1}$ at $230{ }^{\circ} \mathrm{C}$ and $2.16 \mathrm{~kg}, \rho=0.905 \mathrm{~g} \mathrm{~cm}^{-3}$ ) was supplied by Braskem SA (Triunfo, Brazil). Polypropylene grafted with maleic anhydride (PP-g-MA, acidity index of 37-50 mg KOH.g ${ }^{-1}$ ) was supplied by Megh Ind. Com. Ltda. (São Paulo, Brazil) and used as a coupling agent. Curaua fibers, supplied by Embrapa-PA (Belém, Brazil), were milled in a three knife rotary mill (Rone, NFA1533) with a $7 \mathrm{~mm}$ mesh sieve. The fiber length distribution determination was done by image treatment with digital photographs of 400 milled fibers taken from camera (Nikon E-800) coupled to the system for capturing and analyzing images of the Image Pro Plus ${ }^{\circledR}$ Software. The distribution of the fiber length after milling is shown in Figure 1, resulting in a length average numerical value of $3 \mathrm{~mm}$.

\section{Preparation of the composites}

After testing several formulations ${ }^{[16]}$, we choose to prepare composites with 20 wt $\%$ of curaua fibers and $80 \mathrm{wt} \%$ of polypropylene. A range of PP-g-MA contents, from 0 to $4 \mathrm{pph}$ (parts per hundred) calculated in relation to the total weight of the sample, was used. Polypropylene, PP-g-MA and curaua fiber were blended in a mixer (KIE, KA35) during 2 minutes with rotational speed of $1750 \mathrm{rpm}$, and dried in a conventional oven during 1 hour at $100{ }^{\circ} \mathrm{C}$ before extrusion. The composites were processed in a single screw extruder (Wortex, $\mathrm{L} / \mathrm{D}=30, \mathrm{D}=20 \mathrm{~mm}$ ), with screw rotation speed of $100 \mathrm{rpm}$, temperature profile of 170, 180, 190, 190 and $180{ }^{\circ} \mathrm{C}$ from feed to die and degassing. The composites were cooled in water, granulated, dried in a conventional oven for 1 hour at $100{ }^{\circ} \mathrm{C}$ and injection molded into test specimens according to ASTM D638-02 and ASTM D790-02 for tensile and flexural tests, respectively. The temperature profile used in the injection molding machine (Arburg, All-rounder M250) from hopper to nozzle was $185,195,200,205$ and $200{ }^{\circ} \mathrm{C}$, with $120 \mathrm{MPa}$ of injection pressure, $90 \mathrm{MPa}$ of holding pressure, holding time of $5 \mathrm{~s}$, injection velocity of $20 \mathrm{~cm}^{3} \cdot \mathrm{s}^{-1}$, mold temperature of $20^{\circ} \mathrm{C}$ and $10 \mathrm{~s}$ of cooling time.

\section{Morphology}

The cryogenic fracture surfaces of the composites were analyzed by scanning electron microscopy (SEM, Jeol, JSM$6360 \mathrm{LV}$ ) at an accelerating voltage of $25 \mathrm{kV}$. Composites were maintained for 30 minutes in liquid nitrogen before fracture and

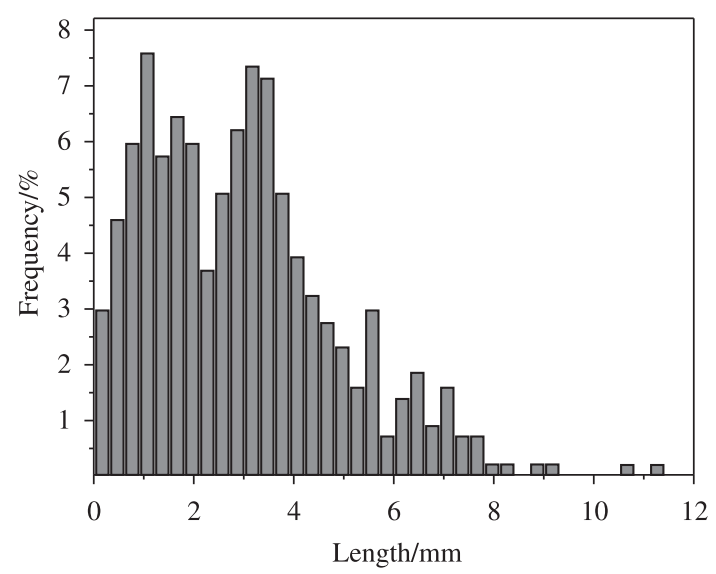

Figure 1. Fiber length distribution of the curaua fibers after milling. sputter-coated (Bal-Tec, Mult Coating System MED020) with Pt/ $\mathrm{Au}(80: 20)$ before analysis. Samples were prepared from the tensile test bars that showed the closest values to the average in the tensile mechanical tests.

\section{Mechanical tests}

The specimens were conditioned for 72 hours at $23( \pm 5)^{\circ} \mathrm{C}$ and at $50( \pm 5) \%$ room humidity before the mechanical tests. Tensile and flexural tests were carried out in an universal testing machine (EMIC, DL2000) with load cell of $5 \mathrm{kN}$. Tensile tests were carried out according to ASTM D638-02, with a crosshead speed of $5 \mathrm{~mm} \mathrm{~min} \mathrm{~m}^{-1}$ and an extensometer with a gauge length of $50 \mathrm{~mm}$. Flexural tests were carried out according to ASTM D790-02, with a crosshead speed of $13 \mathrm{~mm} \mathrm{~min}{ }^{-1}$. Ten specimens were tested for each sample and the reported results are an average of at least seven tested specimens. All results were analyzed using Independent Samples t-test at significance level of 0.05 .

\section{Thermogravimetric measurements}

For these measurements, the PP and composite samples, weighing from 5 to $7 \mathrm{mg}$, were collected from the middle portion of the tensile test bar and dried in a conventional oven for 1 hour at $100{ }^{\circ} \mathrm{C}$. Curaua fibers were also dried under the same conditions. The TGA measurements (TA Instruments, TA2900) were performed in the temperature range from 20 to $600{ }^{\circ} \mathrm{C}$, heating rate of $10{ }^{\circ} \mathrm{C} \mathrm{min}^{-1}$, under an inert atmosphere of argon or an oxidative atmosphere of synthetic air, with gas flows of $50 \mathrm{~mL} \cdot \mathrm{min}^{-1}$, for both cases. The parameter chosen for temperature of initiation of weight loss $\left(\mathrm{T}_{\mathrm{i}}\right)$ was the $3 \%$ of weight loss in order to avoid bias in the measurement due to values fluctuation from equipment accuracy. The samples were tested without replicate. The char residues were taken directly from the graph after no more weight variation as a function of temperature.

\section{Results and Discussion}

\section{Morphology}

The morphology of the composites was analyzed by Scanning Electron Microscopy of the cross section of tensile test bars fractured after immersion in liquid nitrogen for 30 minutes. In the micrographies shown in Figure 2, it can be observed that less fiber bundles are present in the samples containing PP-g-MA, indicating that the fibers are more fibrillated and better dispersed in the matrix.

In Figure 3, micrographies with larger magnification, it is possible to observe some discontinuity at the polymer-fiber interface, showing their poor interaction in the absence of the coupling agent (Figure 3a). In the composites with 1, 2 and 4 pph of PP-g-MA (Figures 3b, c, d, respectively), a good wettability of polypropylene on the fiber surface is shown, with the disappearance of empty spaces between polypropylene and fibers.

The interaction between the fibers and the polypropylene matrix in the presence of PP-g-MA results in a better transference of mechanical stresses having, as a consequence, a more efficient distribution of mechanical efforts, explaining the mechanical properties discussed below.

\section{Mechanical properties}

The mechanical properties of the composites were evaluated in comparison with the polymeric component and the composite with no coupling agent (Figure 4 and Table 1). The comparison 


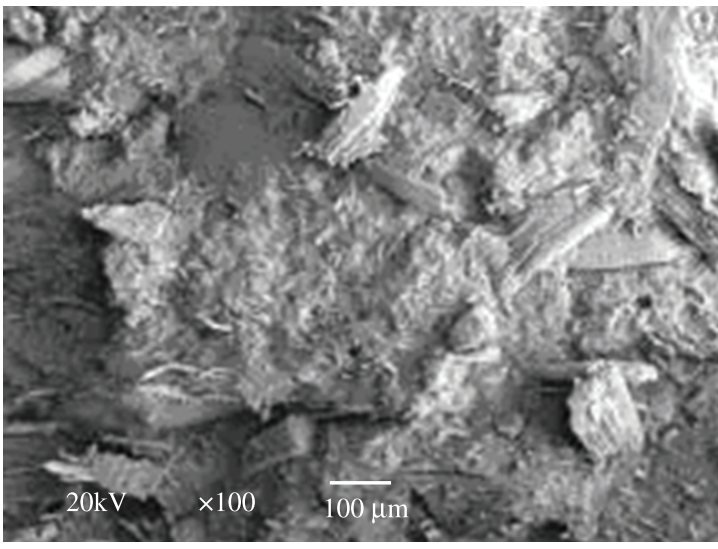

(a)

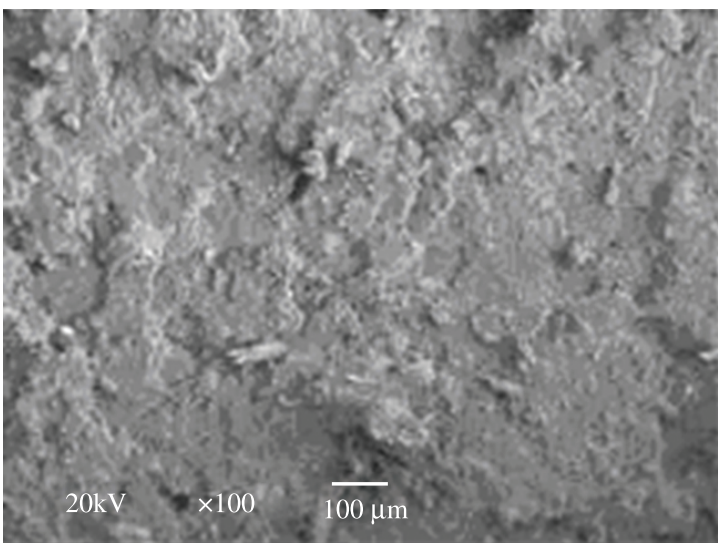

(c)

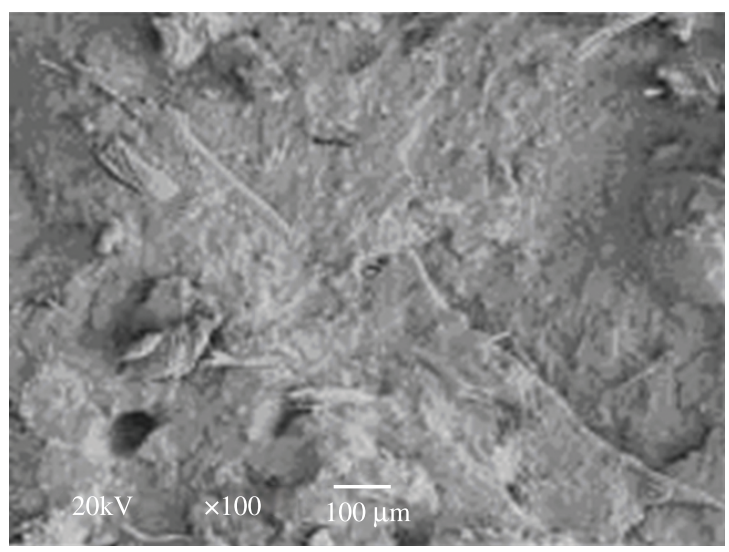

(b)

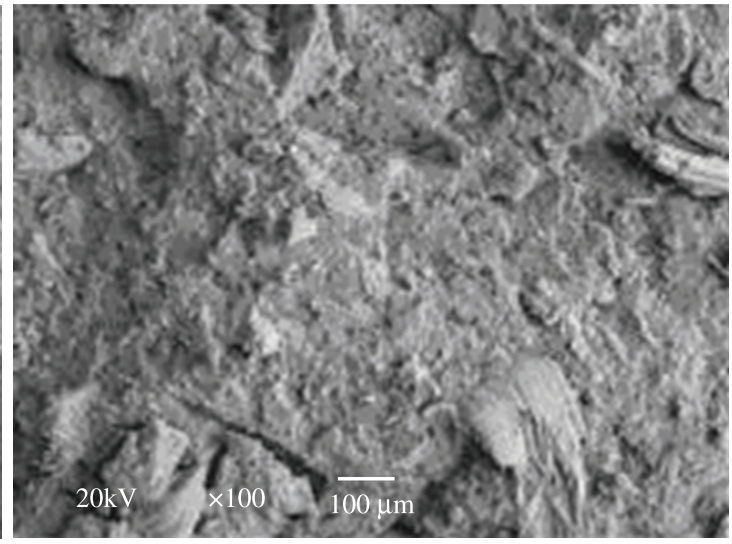

(d)

Figure 2. SEM micrographs of composites with no coupling agent (a), with 1 pph of PP-g-MA (b), 2 pph of PP-g-MA (c) and 4 pph of PP-g-MA (d).

between the first and second lines of Table 1 shows the influence of adding curaua fiber to polypropylene. The comparison between the second and the following lines of Table 1 shows the influence of increasing concentration of PP-g-MA on the mechanical properties of composites.

Analyzing the mechanical properties obtained on tensile mode, tensile strength and modulus of PP did not increase significantly by the addition of $20 \mathrm{wt} \%$ of curaua, however, when the PP-gMA was added to the formulation (1,2 and $4 \mathrm{pph}$ ), an increase on tensile strength was observed, but without significant influence of concentration from 1 to $4 \mathrm{pph}$. This means that, in the concentration range studied, there is no increase in mechanical properties on tensile mode as a function of PP-g-MA concentration. The only property that presented variation on tensile mode after adding curaua fiber was the elongation at rupture, as expected because the fiber is a matrix discontinuity, but even this property did not present any significant variation as a function of PP-g-MA concentration.

The mechanical properties on flexural mode, contrary to the tensile mode, presented a positive variation in the values with the addition of curaua fiber. and increasing of PP-g-MA content. The Young modulus (tensile test) presented no gain in mechanical properties of composites with the addition and increasing concentration of PP-g-MA. The sensitivity of the composite's strength to the presence of PP-g-MA is evidenced in Table 1. The strength is measured in a region where the material is being mechanically stressed to the limit. In this stage, the interface between the polymer and the fiber plays an important role and the adhesion or the lack of adhesion is reflected in the results. The results presented in Table 1 show that the addition of PP-g-
MA increases the strength of composites in both testing modes, flexural and tensile. It is important to remark that the tensile strength on tensile and flexural mode increased around $20 \%$ with the PP-g-MA addition. These results corroborate with the increase of fiber/matrix adhesion with PP-g-MA as a compatibilizer. The elongation at rupture, in tensile tests, presented significantly lower values for composites with PP-g-MA, in comparison with the composite without coupling agent, also because of influence of PP-g-MA as an adhesion promoter.

\section{Thermal degradation}

Figure 5 shows the thermogravimetric curves and their first derivatives, obtained in inert atmospheres, for the composite and its components, without coupling agent and prepared in a single screw extruder. For determining stability, we calculated the expected curve from the component's thermogravimetric curve weight mean ${ }^{[17]}$. The weight mean is calculated from thermogravimetric results obtained for composite components in the percentage used for each one. This expected curve is the result which would be obtained if there were no interaction between degradative processes. The composites whose curves are located below the expected curve are less stable than expected if there were no interaction between degradative processes, showing antagonistic interactions. If the opposite occurs, is evidence of synergistic interaction.

In comparison with the expected result, the composite presented a higher thermal stability, with a shift of $16{ }^{\circ} \mathrm{C}$ in $\mathrm{T}_{\mathrm{i}}$ (Figure 5a and Table 2) and $32{ }^{\circ} \mathrm{C}$ in $\mathrm{T}_{\text {max }}$ (Figure $5 \mathrm{~b}$ and Table 2), because of the synergistic interaction among the degradation processes. As the shift of the $\mathrm{T}_{\max }$ value was significantly larger than the offset value 


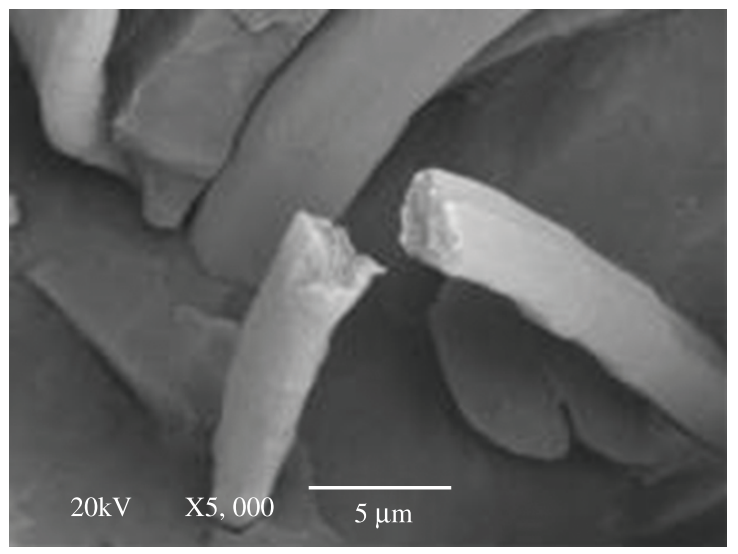

(a)

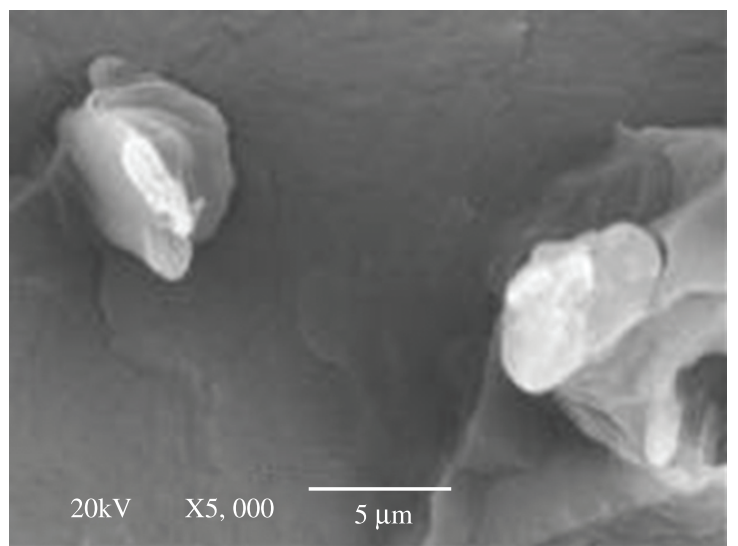

(c)

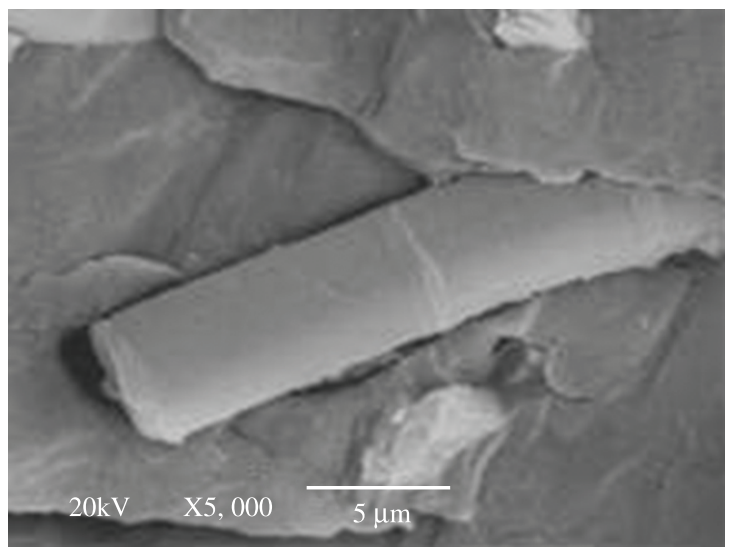

(b)

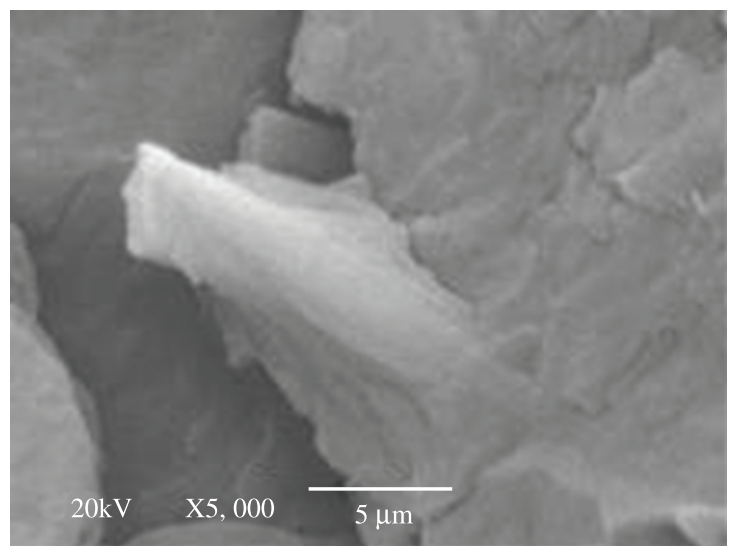

(d)

Figure 3. SEM micrographs of composites without coupling agent (a), with 1 pph of PP-g-MA (b), 2 pph of PP-g-MA (c) and 4 pph of PP-g-MA (d).

Table 1. Mechanical properties for PP and composites: tensile strength ( $\sigma \mathrm{max})$, modulus (E) and elongation at rupture ( $(\varepsilon)$. Mean values followed by same letters in the column do not show statistical difference $(\mathrm{p} \geq 0.05)$.

\begin{tabular}{|c|c|c|c|c|c|c|c|c|c|c|}
\hline \multirow{2}{*}{$\begin{array}{c}\text { Samples } \\
\text { Parts per hundred of PP-g-MA }\end{array}$} & \multicolumn{5}{|c|}{ Tensile mode } & & \multicolumn{4}{|c|}{ Flexural mode } \\
\hline & $\sigma_{\max }(\mathbf{M P a})$ & & E (GPa) & & $\varepsilon(\%)$ & & $\sigma_{\max }(\mathbf{M P a})$ & & E (GPa) & \\
\hline PP & $27.0 \pm 0.5$ & $\mathbf{a}$ & $1.8 \pm 0.2$ & a & $>100 \%$ & $\mathbf{a}$ & $38.3 \pm 0.9$ & $\mathbf{a}$ & $1.1 \pm 0.1$ & a \\
\hline 0 & $28.0 \pm 0.8$ & $\mathbf{a}$ & $2.0 \pm 0.3$ & $\mathbf{a}$ & $5.7 \pm 1.1$ & b & $45.4 \pm 0.7$ & b & $1.8 \pm 0.1$ & b \\
\hline 1.0 & $34.4 \pm 0.7$ & b & $2.1 \pm 0.6$ & a & $4.5 \pm 0.4$ & b & $52.9 \pm 1.7$ & c & $1.9 \pm 0.2$ & b \\
\hline 2.0 & $33.7 \pm 1.9$ & b & $2.0 \pm 0.5$ & a & $4.1 \pm 0.5$ & b & $56.8 \pm 1.1$ & e & $2.1 \pm 0.1$ & b \\
\hline 4.0 & $33.7 \pm 1.1$ & b & $2.2 \pm 0.2$ & a & $4.2 \pm 0.4$ & b & $54.5 \pm 0.9$ & d & $2.0 \pm 0.1$ & b \\
\hline
\end{tabular}

of $T_{i}$, we may conclude that the kinetics of formation and release of volatiles became slower. The first derivative curves show with more details the improvement of thermal stability because of the mixing of PP and curaua fiber (Figure 5b). The differences in production of char residues also presented significant results, with $4.8 \%$ of char formation for the expected values, calculated from the weighed mean curve from the components, against $1.5 \%$ for the experimental results: a reduction of $73 \%$ of char residues produced in comparison with the expected value (Table 2). This result shows the synergistic advantages of mixing the vegetal fibers with the PP polymeric matrix for tertiary recycling, because of its improved transformation of matter into energy during combustion. Regarding the char formation, mixtures of cellulose, hemicellulose and lignin were studied by thermogravimetric analysis and no interaction between their degradation processes was observed ${ }^{[18]}$. However, there are differences when comparing the results obtained with mixtures and the results from natural fibers; there is a visible interaction between the fiber components. This probably happens owing to the presence of mineral contaminants in the fibers, influencing the degradation. The differences observed in our work, lower values for char residues in relation to the expected by calculating the weighed mean, can be partly explained by the dilution of these mineral contaminants in the polymeric domain.

The thermogravimetric curves obtained under oxidative atmospheres (Figure 6a) show the same comparison between the expected and obtained curves, but with less remarkable differences. The difference between the obtained and the expected results for $\mathrm{T}_{\mathrm{i}}$ values is $2{ }^{\circ} \mathrm{C}$, approximately the value of equipment accuracy, meaning no significant differences. However, the shift in $\mathrm{T}_{\max }$ is $22{ }^{\circ} \mathrm{C}$ higher for the result obtained in comparison to the calculated one, as shown in Figure 6b. This difference shows that, in spite of the almost coincident thermogravimetric results for the expected and obtained values of $\mathrm{T}_{\mathrm{i}}$ in an oxidative atmosphere, there is a significant shift of the degradation process of weight loss during 

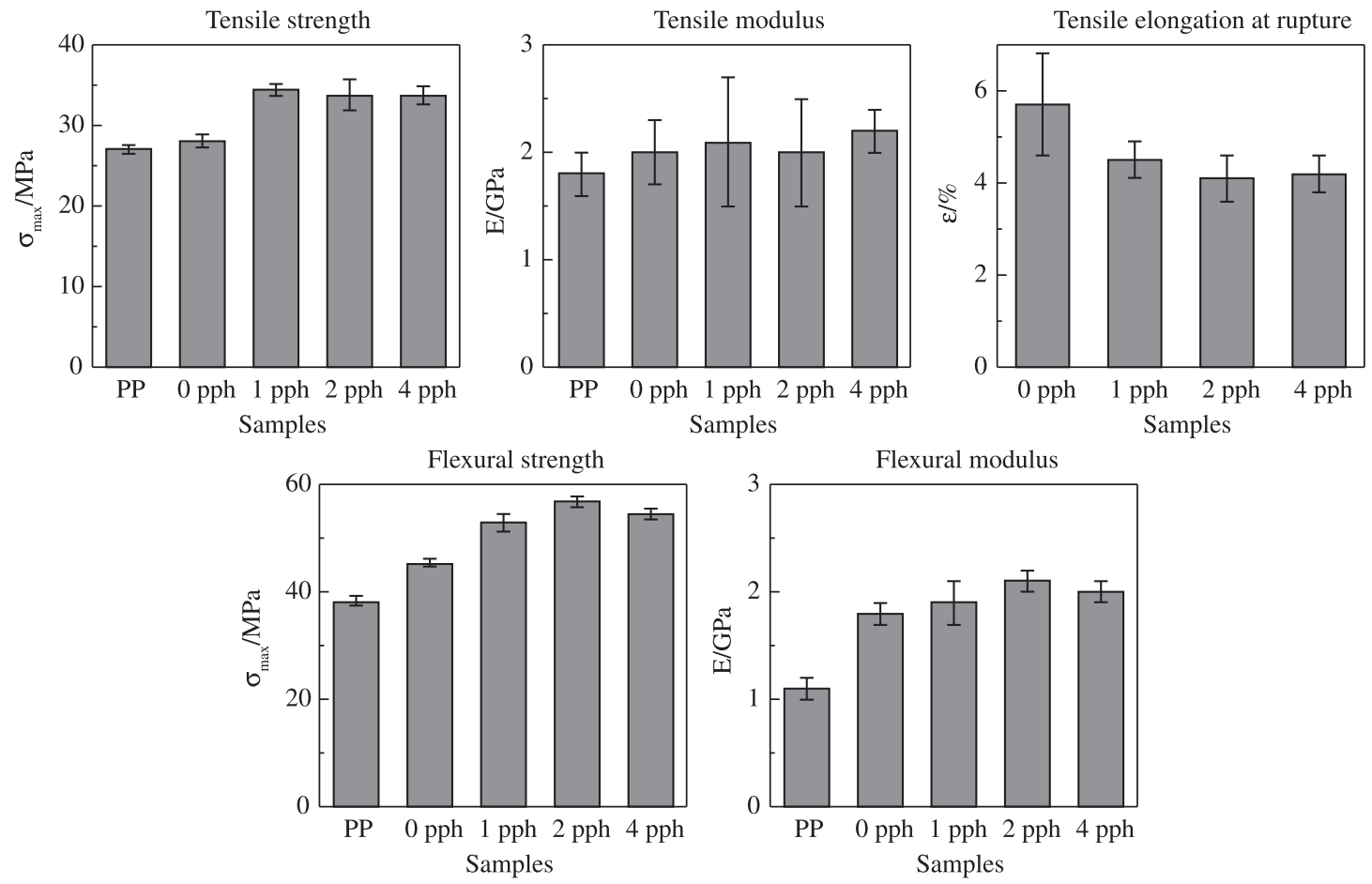

Figure 4. Results of the tensile and flexural mechanical tests of PP and composites without and with 1, 2 and 4 pph of PP-g-MA.

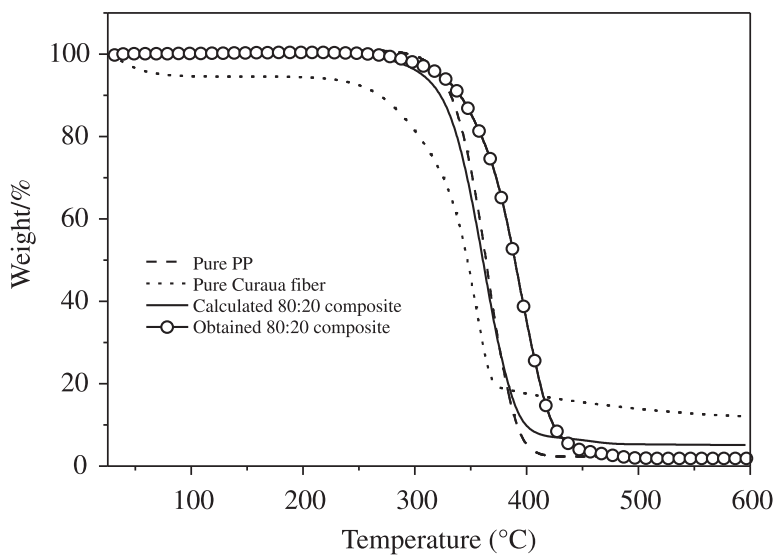

(a)

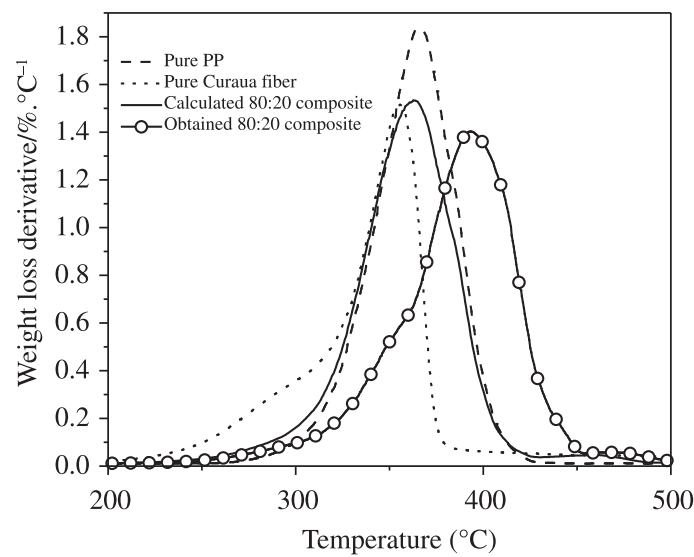

(b)

Figure 5. Thermogravimetric curves obtained under inert atmosphere (a) and their first derivatives (b): comparison between pure components, composite obtained in the single screw extruder and expected curve.

Table 2. Parameters obtained from the thermogravimetric data of PP, curauá fiber and the composite prepared in the single screw extruder: experimental and expected values.

\begin{tabular}{|c|c|c|c|c|c|c|c|}
\hline & Material & $\mathbf{T}_{\mathbf{i}}\left({ }^{\circ} \mathbf{C}\right)$ & $\begin{array}{l}\Delta^{*} \\
\left({ }^{\circ} \mathbf{C}\right)\end{array}$ & $\mathbf{T}_{\max }\left({ }^{\circ} \mathbf{C}\right)$ & $\begin{array}{c}\Delta^{*} \\
\left({ }^{\circ} \mathbf{C}\right)\end{array}$ & $\begin{array}{c}\text { Char residues } \\
(\%)\end{array}$ & $\begin{array}{l}\Delta^{*} \\
(\%)\end{array}$ \\
\hline \multirow{4}{*}{ Inert } & Pure PP & 316 & - & 355 & - & 2.0 & - \\
\hline & Pure Curaua Fiber & $258^{+}$ & - & 365 & - & 11.8 & - \\
\hline & Expected Composite & 295 & 16 & 362 & 32 & 4.8 & 3.5 \\
\hline & Obtained Composite & 311 & $(+5 \%)^{* * *}$ & 394 & $(+9 \%)^{* * *}$ & 1.5 & $(-73 \%)^{* *}$ \\
\hline \multirow{4}{*}{ Oxidative } & Pure PP & 243 & - & 284 & - & 0.6 & - \\
\hline & Pure Curaua Fiber & $254^{\dagger}$ & - & 323 & - & 1.7 & - \\
\hline & Expected Composite & 244 & 2 & 286 & 22 & 0.8 & 0.1 \\
\hline & Obtained Composite & 246 & $(+0.8 \%)^{* *}$ & 308 & $(+8 \%)^{* * *}$ & 0.7 & $(-13 \%)^{* *}$ \\
\hline
\end{tabular}

*The difference between the Obtained result and the Expected value. **Percentage variation of the experimental results compared to the values calculated from the weighed mean of the composite components. $†$ Measured after moisture loss. 
the main weight loss process, between 220 and $350{ }^{\circ} \mathrm{C}$. Thus, concerning the shift of the $\mathrm{T}_{\max }$ values relative to $\mathrm{T}_{\mathrm{i}}$, also in oxidative atmosphere, we can conclude that the kinetics of formation and release of volatiles became slower. Comparing the experimental and expected results, it is observed that the process of weight loss of PP (ca. $290^{\circ} \mathrm{C}$ ) was shifted to higher values, while the process of weight loss of curauá fiber $\left(\mathrm{ca} .330^{\circ} \mathrm{C}\right)$, not presented displacement in comparison with the expected curve. Because of the overlapping of processes, the weight loss of curaua fiber in the composite is in the form of a shoulder in approximately $330{ }^{\circ} \mathrm{C}$.

The zoom inside the graph of the first derivative curves (Figure 6b) shows a shift of $\mathrm{T}_{\max }$ to higher temperatures for the second process of weight loss of curaua fiber, generally attributed to the lignin process of thermal weight $\operatorname{loss}^{[19,20]}$ probably because of that two reasons: the higher hindrance of oxygen access to the fibers in the composite bulk, in comparison to the conditions for curaua fibers analyzed alone, and the stabilization effect caused by the lignin present in the fibers ${ }^{[21,22]}$.

In this study, PP grafted with maleic anhydride (PP-g-MA) was used as a coupling agent for the composite in concentrations of 1,2 and $4 \mathrm{pph}$. The thermogravimetric results in inert atmospheres for composites with PP-g-MA are shown in Figure 7 and the data are reported in Table 3. The increase of coupling agent concentration does not influence the onset temperature, but it shifts the weight loss

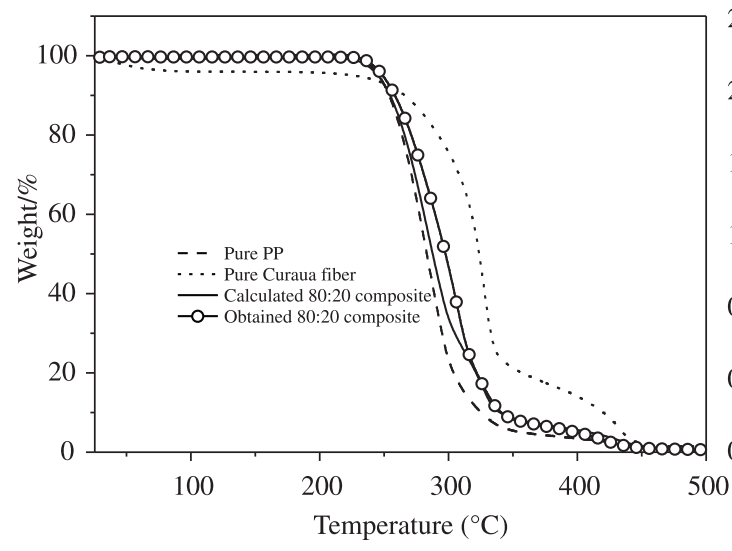

(a)

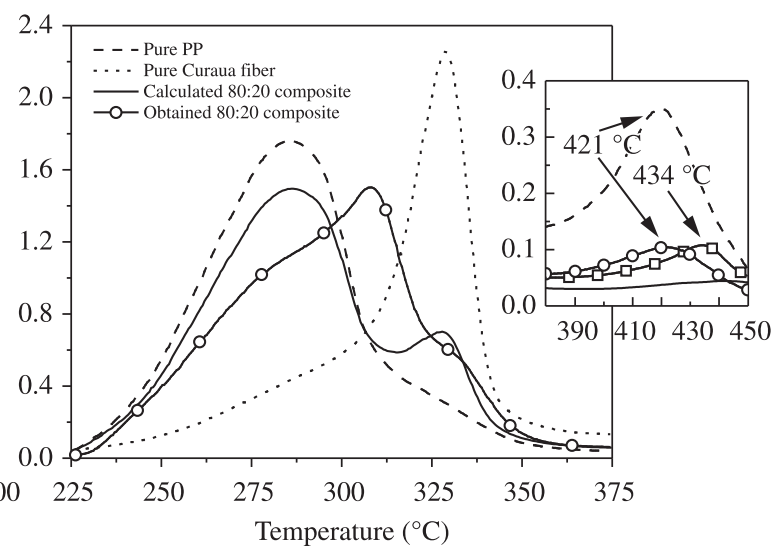

(b)

Figure 6. Thermogravimetric curves obtained under oxidative atmosphere (a) and their first derivatives (b): composite obtained in the single screw extruder, components and the expected curve calculated from weight mean of composite components.

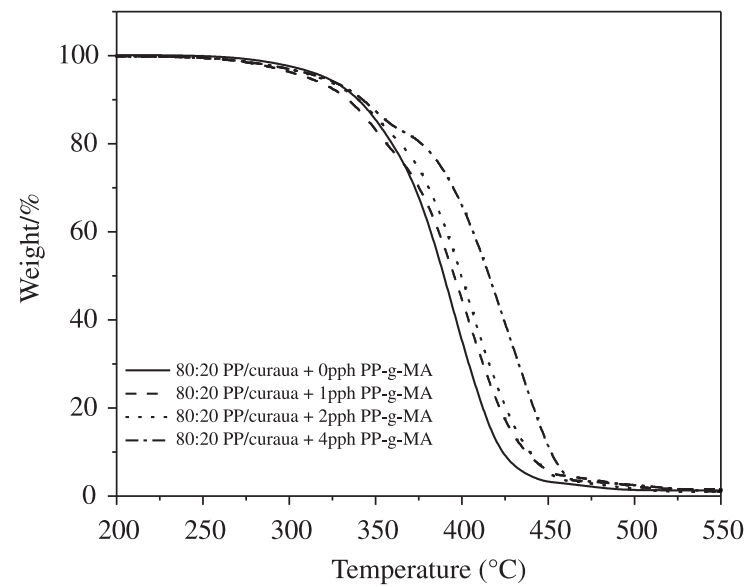

(a)

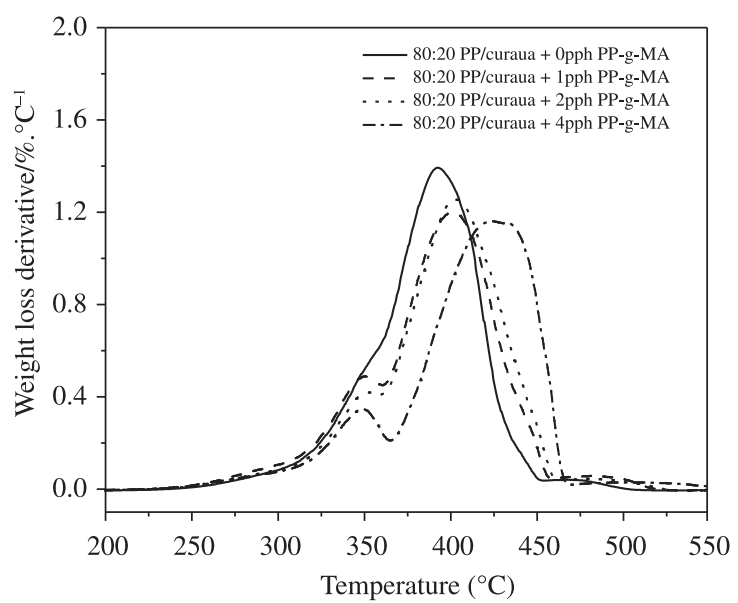

(b)

Figure 7. Thermogravimetric curves (a) and first derivatives (b) obtained under inert atmosphere, of composites without and with 1, 2 and 4 pph of PP-g-MA as a coupling agent.

Table 3. Thermogravimetric parameters, under inert and oxidative atmosphere, obtained for the composites prepared in the single screw extruder with and without coupling agent.

\begin{tabular}{clccc}
\hline & Material & $\mathbf{T}_{\mathbf{i}}\left({ }^{\circ} \mathbf{C}\right)$ & $\mathbf{T}_{\text {max }}\left({ }^{\circ} \mathbf{C}\right)$ & Char residues $(\%)$ \\
\hline & $80: 20$ PP/curaua + 0 pph PP-g-MA & 311 & 394 & 1.5 \\
Inert atmosphere & $80: 20$ PP/curaua + 1 pph PP-g-MA & 298 & 402 & 1.7 \\
& $80: 20$ PP/curaua + 2 pph PP-g-MA & 304 & 404 & 1.2 \\
& $80: 20$ PP/curaua + 4 pph PP-g-MA & 304 & 431 & 1.0 \\
\hline \multirow{5}{*}{ Oxidative atmosphere } & $80: 20$ PP/curaua + 0 pph PP-g-MA & 246 & 302 & 0.7 \\
& $80: 20$ PP/curaua + 1 pph PP-g-MA & 246 & 304 & 0.6 \\
& $80: 20$ PP/curaua + 2 pph PP-g-MA & 243 & 308 & 1.0 \\
& $80: 20$ PP/curaua + 4 pph PP-g-MA & 243 & 310 & 0.7 \\
\hline
\end{tabular}




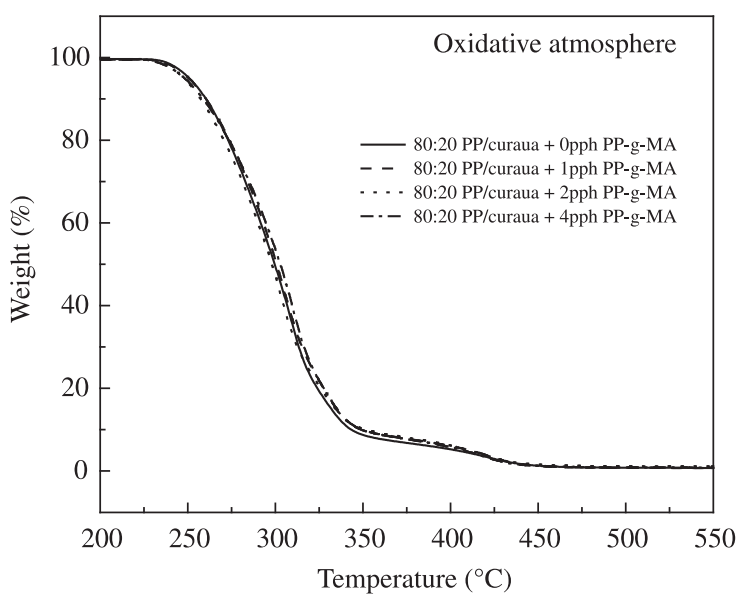

(a)

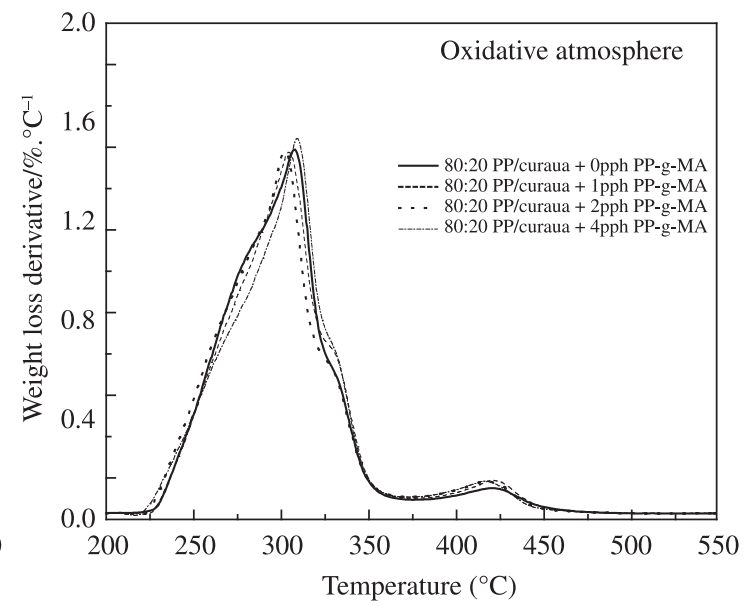

(b)

Figure 8. Thermogravimetric curves (left) and first derivatives (right) obtained under oxidative atmosphere, of composite without and with 1, 2 and 4 pph of PP-g-MA as a coupling agent.

maximum to higher temperatures, as evaluated by $\mathrm{T}_{\max }$. In Figure 7 it is possible to observe two distinct processes of weight loss as a function of the increasing concentrations of PP-g-MA. This is better evidenced in Figure $7 \mathrm{~b}$ where the initial part of the main weight loss process remains unshifted, while the second part is shifted to higher temperature. This clearly indicates that the presence of the coupling agent is affecting only one of the thermal degradation processes of the composite. However, it is not possible to individualize this effect because the coupling agent is interacting with both components of the composite. Additional evidence is the broadening of the second peak in the first derivative curve of the composite with $4 \mathrm{pph}$ of coupling agent. The residual weight at the end of the analysis (char residues) is similar for all samples.

The composites analyzed under inert atmospheres, as discussed earlier, present different behavior when analyzed under oxidative atmospheres. In this condition, the composites did not show any significant difference in weight loss processes as a function of PP-gMA presence or concentration, Figure 8 and Table 3. This difference is probably because the polar groups and residual hydroperoxide present in the PP-g-MA are the main sources of oxygenated groups to cycle auto-catalytic polymeric degradation in inert atmosphere, while in oxidative atmosphere the main source of oxygen for oxidative reactions is oxygen gas, minimizing the importance of the PP-g-MA as a source of oxidative degradation, under the conditions studied.

The analysis of the Tmax values for the oxidative atmosphere (Table 3) seems to present a trend to variation depending on the concentration of PP-g-MA, however the proximity of values, and the fact that there is no duplicate of the analyzes, make difficult to confirm this hypothesis.

\section{Conclusion}

The better dispersion and wettability of the fibers obtained by addition of PP-g-MA, and evidenced in the SEM micrographs, was the reason to achieve good mechanical performance for the composites. Differences in thermal stability of the composites as a function of the atmosphere and the concentration of PP-g-MA were observed. The composites processed without PP-g-MA presented less stable behavior in inert atmospheres, while in oxidative atmospheres these parameters had no significant variation. The presence of the coupling agent, PP-g-MA, in the composites caused significant stabilizing effects as a function of its concentration under inert atmospheres, while under oxidative atmospheres the composites did not show variation in thermal stability as a function of the PP-g-MA presence and concentration.

\section{Acknowledgements}

Authors thank financial support from FAPESP (Grant 2010/17804-7) and BM acknowledges a fellowship (06/58343-7). We also thank Braskem, Megh SA Ind e Com and Embrapa-PA for supplying the samples.

\section{References}

1. Joshi, S. V.; Drzal,L. T.; Mohanty,A. K. \& Arora, S. - Compos.: Part A, 35, p.371 (2004). http://dx.doi.org/10.1016/j.compositesa.2003.09.016

2. Leão, A. L.; Caraschi, J. C.; Tan, I. H.; Kozlowski, R. \& Many, S. - Plástico Ind., 31, p.214 (2001).

3. Zah, R.; Hischier, R.; Leao, A. L. \& Braun, I. J. - Cleaner Prod., 15, p.1032 (2007). http://dx.doi.org/10.1016/j.jclepro.2006.05.036

4. Baillif, M. \& Echtermeyer, A. J. Appl. Pol. Sci., 115, p.2794 (2010). http://dx.doi.org/10.1002/app.30421

5. Bengtsson, M.; Baillif, M. \& Oksman, K. Compos.: Part A, 38, p.1922 (2007). http://dx.doi.org/10.1016/j.compositesa.2007.03.004

6. Balzer, P. S.; Vicente, L. L.; Briesemeister, R.; Becker, D.; Sordi, V.; Rodolfo Junior, A. \& Feltran, M. B. Polímeros, 17, p.1 (2007). http:// dx.doi.org/10.1590/S0104-14282007000100004

7. Silva, R.; Haraguchi, S. K.; Muniz, E. C. \& Rubira, A. F. - Quim. Nova, 32, p.661 (2009). http://dx.doi.org/10.1590/S010040422009000300010

8. Joseph, P.V., Joseph, K. \& Thomas, S. - Compos. Sci. Technol., 59, p.1625 (1999). http://dx.doi.org/10.1016/S0266-3538(99)00024-X

9. Bledski, A. K. \& Gassan, J. - Prog. Polym. Sci., 24, p.221 (1999).

10. Santos, P. A.; Spinace, M. A. S.; Fermoselli, K. K. G. \& De Paoli, M. A.- Polimeros, 19, p.31 (2009).

11. Santos, E. S.; Moresco, M.; Rosa, S. M. L. \& Nachtigall, S. M. B. - Polímeros, 20, p.215 (2010). http://dx.doi.org/10.1590/S010414282010005000036

12. Bettini, S. H. P. \& Agnelli, J. A. M. - Polym. Test., 19, p.3 (2000). http://dx.doi.org/10.1016/S0142-9418(98)00066-X

13. Araujo, J. R.; Waldman, W. R. \& De Paoli, M. A. - Polym. Degrad. Stab., 93, p.1770 (2008). 
14. Satyanarayana, K. G.; Guimarães, J. L. \& Wypych, F. - Compos.

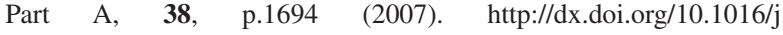
compositesa.2007.02.006

15. Santos, P. A.; Spinace, M. A. S.; Fermoselli, K. K. G. \& De Paoli, M. A. - Compos.: Part A, 38, p.2404 (2007). http://dx.doi.org/10.1016/j. compositesa.2007.08.011

16. Spinacé, M. A. S.; Lambert, C. S.; Fermoselli, K. K. G. \& De Paoli, M. A. - Carbohydr. Polym., 77, p.47 (2009). http://dx.doi.org/10.1016/j. carbpol.2008.12.005

17. Waldman, W. R. \& De Paoli, M. A. - Polym. Degrad. Stab. 60, p.301 (1998). http://dx.doi.org/10.1016/S0141-3910(97)00083-9

18. Yang, H.; Yan, R.; Chen, H.; Zheng, C.; Lee, D. H. \& Liang, D. T. - Energy \& Fuels, 20, p.388 (2006). http://dx.doi.org/10.1021/ ef0580117
19. Hatakeyama, T. \& Hatakeyama, H. - "Thermal Properties of Green Polymers and Biocomposites", Kluwer Academic Publishers, New York (2005).

20. Canetti, M.; Bertini, F.; Chirico, A. D. \& Audisio, G. - Polym. Degrad. Stab., 91, p.494 (2008). http://dx.doi.org/10.1016/j. polymdegradstab.2005.01.052

21. Kosikova, B.; Gregorova, A.; Osvald, A. \& Krajcovicova, J. - Appl. Pol. Sci., 103, p.1226 (2007)

22. De Paoli, M. A.; Rodrigues, M. A. \& Furlan, L. T. - Polym. Degrad. Stab., 13, p.337 (1985).

Received: $28 / 12 / 11$

Revised: $11 / 07 / 12$

Accepted: 16/08/12 